\title{
Successes and unintended consequences of the Northern Territory's smoke-free prisons policy: results from a process evaluation
}

\author{
${ }^{a}$ Menzies School of Health Research, Darwin, Northern Territory, Australia \\ ${ }^{b}$ Northern Territory Department of Correctional Services, Darwin, Australia \\ c Corresponding author: marita.hefler@menzies.edu.au
}

Marita Heflera,c, Robyn Hopkins ${ }^{b}$ and David P Thomas ${ }^{a}$

\section{Article history}

Publication date: April 2016

Citation: Hefler M, Hopkins R, Thomas DP. Successes and unintended consequences of the Northern Territory's smoke-free prisons policy: results from a process evaluation. Public Health Res Pract. 2016;26(2):e2621619. doi: http://dx.doi. org/10.17061/phrp2621619

\section{Key points}

- A long lead-in time and a comprehensive awareness campaign generated acceptance of the smoke-free prisons policy, and ensured that prisoners and staff were well prepared

- Planning for similar policies in other jurisdictions should carefully assess prisoners' preferred quitting options

- Diversion and misuse of nicotine replacement therapy (NRT) patches were unintended consequences of the policy

- Implementation of a smoke-free prisons policy should include strategies to minimise opportunities for NRT diversion

\section{Abstract}

Objectives: In 2013, the Northern Territory was the first Australian jurisdiction to introduce a smoke-free policy for all correctional facilities. We report on a process evaluation to identify what worked well, key challenges and unintended consequences.

Methods: We interviewed 87 people, comprising remand, medium-security and low-security prisoners; visiting family members; and prison staff (including prison management and health workers). A realist evaluation approach was used.

Results: A long lead-in time, collaborative planning and a comprehensive communication strategy were vital for generating support for the policy and ensuring a smooth transition, with no riots or major incidents. Many prisoners expressed a preference for cessation support options other than nicotine replacement therapy (NRT). An unintended consequence was misuse of NRT patches.

Conclusions: A comprehensive approach to creating support among staff and prisoners is important for smooth implementation of policies for smokefree prisons. Planning should include assessment of prisoners' preferred form of cessation support and strategies to minimise NRT diversion.

\section{Introduction}

Correctional centres are increasingly adopting smoke-free policies, driven by workplace health and safety concerns, and litigation risks from exposure to second-hand smoke. The legal obligation to implement strategies for smoke-free environments, including prisons, is mandated by the World Health Organization Framework Convention on Tobacco Control. ${ }^{1}$ However, policies vary, partly because prisons are both workplaces and individuals' homes. ${ }^{2}$

Smoking in Australia is associated with factors that include mental health issues, substance use disorders, low educational attainment, unemployment, homelessness and social isolation. ${ }^{3}$ Smoking prevalence among Indigenous 
Australians, the most systematically disadvantaged group in Australia, is approximately twice the Australian average. ${ }^{3}$ Prisoners are disproportionately drawn from these groups, with correspondingly high smoking prevalence; the 2012 National Prisoner Health Data Collection found that $84 \%$ of prison entrants were current smokers. ${ }^{4}$ However, $46 \%$ of prison entrants who were smokers expressed a desire to quit, similar to the level in the general population. On exit, 35\% of dischargees had attempted to quit while incarcerated, but only $8 \%$ were successful. ${ }^{4}$

In July 2013, the Northern Territory (NT) was the first Australian jurisdiction to introduce smoke-free policies in all prisons. The NT has Australia's highest proportion of Indigenous prisoners $(85 \%)^{5}$ and highest adult smoking prevalence (32\% in 2011-13). ${ }^{6}$ Among Indigenous males, prevalence in the period 2011-2012 was 66\%, compared with $28 \%$ for non-Indigenous males; for Indigenous women, it was $47 \%$, compared with $20 \%$ for nonIndigenous women. ${ }^{6}$

The NT policy is intended to promote healthy lifestyles, and protect nonsmoking prisoners, visitors and staff from second-hand smoke. Policy implementation used a comprehensive approach - for staff, it included 'Quit' training and information sessions; for prisoners, it included Quit groups, free nicotine replacement therapy (NRT) (6-12 weeks, depending on individual needs) and free unmonitored access to a telephone Quitline. NRT and Quitline were available for 2 years before the ban. Support also included healthy lifestyle components, such as additional sport and healthy food options, to help individuals manage nicotine withdrawal. A communication and information strategy - to raise awareness and generate support among staff, prisoners and the general community - included posters, banners, announcements, daily countdowns to the start of the ban, prison events (e.g. a concert with visiting officials to promote the benefits of being smoke-free) and a media campaign. The strategy started more than 12 months before the policy came into force. It was designed in conjunction with staff and prisoners, and driven by the Principal Health Advisor at the NT Department of Correctional Services head office.

The international evidence for effectiveness of correctional smoke-free policies on smoking behaviour is mixed ${ }^{6-12}$ and research has typically been undertaken in facilities with poor compliance. ${ }^{13}$ The NT policy was modelled on that of New Zealand, where, in 2011, a national smoke-free prisons policy was implemented without riots or other major incidents. ${ }^{14}$ Smoke-free prisons policies frequently attract concern that removing "one of the few pleasures" and a stress management tool from prisoners will result in riots and increased violence. ${ }^{15} \mathrm{NRT}$, part of standard smoking cessation treatment guidelines ${ }^{16}$, can be considered a risk mitigation strategy to make the transition less stressful for prisoners by reducing nicotine withdrawal symptoms, thereby decreasing the likelihood of such incidents. It also adheres to the 'equivalence of care' principle for prisoners and the general community. ${ }^{17}$

This article reports on findings from a process evaluation that aimed to identify lessons learnt, successes, challenges, unintended consequences and future research priorities, and provide recommendations for refining the policy. The NT has two prisons, in Darwin and Alice Springs, and two work camps. The evaluation examined implementation at the two prisons.

\section{Methods}

The study was based on a realist evaluation approach ${ }^{18}$, which focused on understanding how the policy was working from the perspective of those directly affected. Data collection was from March to July 2014, and consisted of qualitative interviews with key stakeholders involved in, and affected by, the policy's implementation. Interview topic guides, summarised in Table 1, were developed based on a review of policy documents and communication materials, and discussion with the project manager.

Interviews and small group discussions were used to understand how the policy was implemented on the ground and integrated into prison daily life. Interviews were recorded, with participants' permission. The interview approach was open and inductive, to identify issues based on the day-to-day experiences of prisoners and staff. Emerging issues were incorporated into the interview guide as the study progressed to elicit perspectives from a broad range of participants.

\section{Participant recruitment and sampling}

Prisoners were recruited using two methods: referrals from staff, and information given by the interviewer to prisoners attending education and offence-specific treatment groups. Staff were recruited through printed information and invitations provided at staff meetings, and/or direct approach by the interviewer. Prisoners' family members were given an information sheet in the prison visiting area and invited to approach the interviewer. Smokers and nonsmokers, and policy supporters and opponents were purposively sampled and included in each participant category. We attempted to reach data saturation; however, this was limited by the short time frame and practical constraints of a custodial environment.

\section{Data analysis}

We used a process of thematic analysis, which was both inductive and deductive, to categorise and describe key issues. ${ }^{19}$ Interview recordings were reviewed, and comprehensive notes were made from each interview. These were compared across interviews to build detailed information about issues that arose and to ensure that the diversity of views was included. Recordings were repeatedly reviewed throughout the analysis to compare viewpoints and ensure that no major themes were missed. 
Table 1. Summary of interview discussion guides

\begin{tabular}{llll}
\hline & & & $\begin{array}{l}\text { Staff } \\
\text { (nonmedical, custodial }\end{array}$ \\
& Prisoners & Visiting family members & and noncustodial) \\
Demographic & Remand/custodial sentence & Usual community/town & Current role \\
information & Security rating & Years of custodial \\
& Duration of current custodial & Indigenous status & experience \\
& episode & Relationship to inmate & Experience in other \\
& Previous custodial history & Does the inmate & prisons \\
& Indigenous status & normally live with you? & Indigenous status \\
& Home community and usual & Inmate status (remand/ & \\
& community/town of residence & custodial) and duration & \\
& & of custodial episode &
\end{tabular}

Staff (medical clinic)

Current role

Years of prison health work experience

Experience in other prisons

Indigenous status

\begin{abstract}
Personal smoking status

Smoking status before custody or before ban

If previously a smoker, how many cigarettes per day or week Intention to smoke/not smoke after leaving prison

Whether quitting services provided in custody were used. If so, how helpful were they?
\end{abstract}
Policy impact How easy or difficult have you found being smoke-free in custody?

\section{Current smoking status Smoker/ex-smoker/} Smoking status of family nonsmoker member before custody If current smoker, how many cigarettes per day If ex-smoker, when did you quit? If a smoker when policy started, impact on personal smoking behaviour

Impact of policy on daily work

Observations of impact on prisoner behaviour Have you had to manage any policyrelated incidents?
Smoker/ex-smoker/ nonsmoker

If current smoker, how many cigarettes per day If ex-smoker, when did you quit? If a smoker when policy started, impact on personal smoking behaviour

Involvement in providing cessation services Observations of any changes in presenting health issues since policy was introduced

\section{Communication If in prison when the policy and awareness started, were you informed about it? How did you learn about it and what were you told? If you came into custody after the policy started, did you know about the policy before you entered prison? How/what did you know about it?}

\begin{tabular}{ll}
\hline Attitudes & Personal support for the policy - \\
before and now
\end{tabular}

Expectations of inmate smoking after release Attitude to supporting/ not supporting inmate to be smoke-free following release

\section{Communication received about the policy before implementation}

\begin{tabular}{|c|c|c|c|c|}
\hline Open questions & $\begin{array}{l}\text { What are the good things about } \\
\text { the policy? } \\
\text { Are there any bad things about the } \\
\text { policy? }\end{array}$ & $\begin{array}{l}\text { What are the good } \\
\text { things about the policy? } \\
\text { Are there any bad } \\
\text { things about the policy? }\end{array}$ & $\begin{array}{l}\text { What are the good } \\
\text { things about the policy? } \\
\text { Are there any bad things } \\
\text { about the policy? } \\
\text { Could it be improved? If } \\
\text { so, how? }\end{array}$ & $\begin{array}{l}\text { What are the good } \\
\text { things about the policy? } \\
\text { Are there any bad things } \\
\text { about the policy? } \\
\text { Could it be improved? If } \\
\text { so, how? }\end{array}$ \\
\hline
\end{tabular}




\section{Ethical issues}

The Menzies School of Health/NT Department of Health Ethics Committee approved the study. Participants were told participation was voluntary and no adverse consequences would result if they declined. Several prisoners and staff declined to participate. The number of refusals is unknown because the interviewer was only informed about participants who agreed; most prisoners were referred by prison staff, and some staff were referred by colleagues. All participants gave written consent.

Participants were assured of individual confidentiality. Systematic policy violations such as contraband tobacco and misuse of NRT patches were reported to head office, without identifying individuals. We explained this obligation to all participants before obtaining consent. There were no reports or evidence of reprisals arising from participation. To avoid potential ramifications for prisoners, we did not ask them directly about their own involvement in policy violations.

\section{Results}

We interviewed 87 people: 59 prisoners, 4 visiting family members and 24 staff (Table 2).

A number of factors essential to successful policy implementation were identified, particularly the comprehensive communication and awareness campaign, the long lead-in time and cessation support. The main unintended consequence was diversion and misuse of NRT patches.

\section{Successful strategies: planning, communication and informal problem solving}

The comprehensive communication strategy and long lead-in time were cited by staff, prisoners and family members as vital to a smooth transition. No riots or major incidents were associated with policy implementation, and no serious prisoner-on-staff assaults had occurred since the policy started.

Multiple communication channels meant that all stakeholders had time to become aware of the policy, and understand its rationale and how it would work. All prisoners interviewed who were in custody in the lead-up to the ban reported being informed about the policy well in advance, and were offered support to adjust to the transition.

Quit training and information about smoke-free policies given to key prison staff ensured that they were able to identify potential problems, and develop appropriate solutions to resolve and manage them. Policy 'champions' emerged among both staff and prisoners, who helped promote engagement and build momentum, allowing people to feel that they were not simply following

Table 2: Participant details, interview durations and formats

\begin{tabular}{|c|c|c|}
\hline $\begin{array}{l}\text { Participant } \\
\text { category }\end{array}$ & $\begin{array}{l}\text { Participant } \\
\text { subcategory }\end{array}$ & Details \\
\hline \multirow[t]{3}{*}{ Staff $(n=24)$} & $\begin{array}{l}\text { Correctional } \\
\text { officers }\end{array}$ & $\begin{array}{l}\text { Uniformed and nonuniformed (sport and recreation) officers and management } \\
\text { participated in face-to-face interviews at Darwin Correctional Centre and phone } \\
\text { interviews from Alice Springs Correctional Centre. Interviews took up to } 45 \text { minutes. Five } \\
\text { interviews were in groups or pairs; all others were individual. }\end{array}$ \\
\hline & $\begin{array}{l}\text { Prisoner support } \\
\text { staff }\end{array}$ & $\begin{array}{l}\text { Nonuniformed, noncorrectional prisoner support and treatment staff participated in } \\
\text { individual face-to-face interviews at Darwin Correctional Centre and phone interviews } \\
\text { from Alice Springs Correctional Centre. They included psychologists and other clinical } \\
\text { treatment providers, education providers, staff from reintegration services and Aboriginal } \\
\text { liaison staff. Interviews took up to } 30 \text { minutes. }\end{array}$ \\
\hline & Health clinic staff & $\begin{array}{l}\text { Primary health care nurses at the correctional centre clinic participated in individual } \\
\text { interviews of up to } 12 \text { minutes. }\end{array}$ \\
\hline Prisoners $(n=59)$ & na & $\begin{array}{l}\text { A mix of medium-security, low-security and remand prisoners were interviewed - } 7 \% \\
\text { were female, roughly equal to the overall representation of } 5 \% \text { in the Darwin Correctional } \\
\text { Centre prison population. Low-security prisoners included current and previous } \\
\text { participants in work release programs and work camps. Of the prisoners interviewed, } \\
75 \% \text { were smokers before introduction of the policy (if incarcerated at that time) or } \\
\text { before entering custody. Around } 85 \% \text { were Indigenous, in line with the overall proportion } \\
\text { within the NT prison population. Five individual and eight small-group discussions (3- } \\
13 \text { people) were undertaken without custodial officers within hearing distance. Interviews } \\
\text { lasted from a few minutes to around } 30 \text { minutes. }\end{array}$ \\
\hline $\begin{array}{l}\text { Family members of } \\
\text { prisoners }(n=4)\end{array}$ & na & $\begin{array}{l}\text { Visiting family members participated in individual face-to-face interviews lasting up to } \\
15 \text { minutes. }\end{array}$ \\
\hline
\end{tabular}

na $=$ not applicable 
a directive imposed from above. Initiatives developed by champions included a prisoner committee, which developed strategies such as sporting activities and the availability of healthier foods for purchase, and worked with respected community leaders to endorse the policy. Formal strategies were complemented and reinforced by staff integrating promotion of the policy into their everyday work with prisoners - they encouraged quit attempts before policy implementation, and discussed the benefits of being smoke-free to foster acceptance:

We said to them: what's your date? Try and make the date before the changeover, it will make it better ... a few of them had a couple of goes, they knew the date was coming, and they looked at other measures, tried different things. They got there in the end. (custodial officer)

I had prisoners telling me before ... "we'll be punching on boss, in a week" ... I used to just promote the patches, "well, now's your time to get on the patches, start doing something proactive" ... (custodial officer)

Prisoners also tried different approaches and offered mutual support:

I just kept myself busy ... playing cards ... drinking lots of water ... I told other prisoners, keep yourself busy, keep your hands busy. It'll help you cope. A couple of boys said, "yeah, it's helping" ...

(prisoner who was in custody when the policy started)

Together, these factors contributed to a culture of change, which was well under way before the policy was implemented.

\section{Prisoner and family member attitudes to the ban}

Attitudes of prisoners and family members towards the ban ranged from a high level of support to implacable opposition. Overall, staff, prisoners and family members who were nonsmokers were more supportive. However, some smokers were supportive, either because they wanted to quit, or because they saw the benefits in hindsight, despite initial anger:

I've been trying to give up the smokes for years ... I'm rapt that I'm off the smokes, because I'll be around for my kids. Cigarettes were the hardest thing to give up ... (prisoner who entered custody after the ban)

I was pretty ticked off about it ... (but now) I'm glad, because I wouldn't have quit ... I would have kept on smoking ... but I'm glad for my health, I don't get up coughing and spluttering anymore ... (prisoner who was in custody when the ban started)
We did not observe significant attitude differences between Indigenous and non-Indigenous participants.

\section{Prisoner attitudes to NRT and preferences regarding cessation}

Many prisoners expressed a preference for options other than NRT to support withdrawal, such as additional sports or other programs, or counselling about coping strategies:

Give them options ... take away the patches, take away the smokes, but they should have something ... more food, more cereal, more programs ... library with more books ... (prisoner who entered custody after the ban)

Many prisoners reported a preference for going 'cold turkey', although several mentioned that they had taken NRT when it was offered, supporting the suspicions of medical staff that patches were obtained to trade, rather than for personal use:

The patches I had, there was this old fella in the dorm I was in ... I just used to give them to him ... (prisoner who entered custody several months after the ban started)

Even if you weren't a smoker, you get patches anyway because you can swap them for food ... (prisoner whose current custodial episode began after the ban started, and had previous custodial episodes)

It would be expected that its value as a currency (as detailed below) was an incentive for accepting NRT, particularly because it was provided for free. During the course of the evaluation, methods were put in place to control how NRT was distributed, and changes were introduced to provide it on request, rather than proactively screening for tobacco dependence and offering NRT. Following these changes, few prisoners requested NRT.

\section{Unintended consequences: NRT diversion and misuse}

Almost all staff and prisoners reported misuse (smoking) of NRT patches as a widespread problem. Although patches had been available to prisoners since May 2011, misuse was reported to have become problematic in the 2-3 months following policy commencement in July 2013, and continued to be problematic at one site at the time of the evaluation. Before the ban, patches were reportedly used to tide prisoners over when their tobacco ran out until 'buy day'. At the time of data collection, prisoners were issued with several days' supply of patches to self-manage, which appears to have contributed to stockpiling, trading and diversion.

Patch smoking was reported as occurring in accommodation blocks (where prisoners were housed in dormitory-style accommodation), primarily at 
night, although some daytime smoking was reported, particularly on days when patches were distributed. Officers and medical staff rostered to accommodation blocks at night reported an unpleasant plastic, rubber or chemical burning smell, which they found irritating to the eyes and throat:

When you go into certain [accommodation] blocks, it's a haze of smoke ... as soon as I walk in, it stinks and you can't even see ... the smell, it's like a burning/chemical smell ... I've never smelt anything like it ... (staff member working in accommodation block at night)

Staff reports were consistent with prisoner reports. Many prisoners and staff were concerned that the smoke might be more toxic than tobacco smoke, to both the smoker and people exposed to second-hand smoke. Several prisoners reported witnessing acute illness in other prisoners, and some believed that at least one death was associated with the practice:

People are smoking patches. It's bad ... I think one of them died from it ... (prisoner who was in custody since before the ban)

People are smoking nicotine patches, tea leaves, which is going to be a lot worse for you in the long run ... I believe there's been four people hospitalised from smoking tea leaves and nicotine patches ... (prisoner who was in custody since before the ban)

Perceptions of hospitalisations and death attributable to smoking patches were reported by several participants, but this was not supported by reports from medical staff or coronial findings. Medical staff reported that they had been requested to examine prisoners after they were alleged by custodial officers to have smoked patches, but not because of observable symptoms. In addition, staff stated that prisoners would not typically disclose whether they had been engaging in illegal activities, making it difficult to verify whether acute illness followed patch smoking. Before this evaluation, there was no published research about the toxicity of smoked patches, making it difficult to assess the likelihood that it would cause symptoms. Details of how patches were smoked and results from an initial chemical analysis of cigarettes made from diverted patches, undertaken in response to this evaluation, are reported elsewhere. ${ }^{20}$

Patches were reported as having value as currency. Multiple sources reported prisoners being 'stood over' for patches, typically having to surrender their entire supply as soon as it was received. It therefore appeared that some prisoners who may have wanted to use patches correctly were unable to do so. Medical staff reported that some prisoners appeared to have overreported tobacco dependence at medical screening in order to obtain patches. They also observed prisoners returning for patches immediately following reception into the facility, having initially reported not wanting or needing patches.
As a result, some staff used more detailed questioning to verify prisoners' self-reports of smoking.

An additional safety concern reported by prisoners and staff was the risk of electrocution from ignition methods used during smoking of patches, including using exposed wires on electrical appliances, inserting objects into power points, and using batteries with the casing peeled back.

\section{Discussion}

This study found that a comprehensive communication and awareness campaign with a long lead-in time was a vital component of introducing a smoke-free policy in NT correctional services without riots or other major incidents. It allowed informal problem solving among prisoners and staff, which provided a mechanism for potential tensions to dissipate before implementation and generated widespread acceptance of the policy. This collaborative approach, based on building support among staff and prisoners, aligns with findings from similar evaluations of smoke-free prisons in New Zealand ${ }^{13}$ and the US ${ }^{21}$, and the introduction of smoke-free policies on US navy submarines in 2010. ${ }^{22}$ It also takes into account lessons learnt from unsuccessful implementation in a mental health inpatient unit. ${ }^{23}$

The evaluation highlights the need to understand prisoners' preferences regarding provision of NRT to assist with abrupt, involuntary cessation. Social cues are a relapse risk factor for smokers who are attempting to, or have recently, quit ${ }^{24}$; residing in a facility where these cues are absent or minimal may reduce the need for NRT. ${ }^{25}$ Further research in the Australian context should focus on identifying effective support mechanisms for motivating and supporting prisoners to maintain abstinence following their release from smoke-free facilities that have relatively high compliance.

An unexpected finding was the reportedly widespread practice of NRT patch diversion and misuse. Although NRT provision is based on standard smoking cessation guidelines and was initially an appropriate riskminimisation strategy, it became the most problematic aspect of what was otherwise a largely problem-free transition. Although patch misuse was raised by almost all interviewees, only a small number of prisoners were receiving patches at any time: once the policy started, provision was limited to 6-12 weeks for newly arrived prisoners. At any time, no more than $15 \%$ of the prisoner population, and usually less than $10 \%$, were receiving patches. In addition, the misuse should be considered in the context of the range of issues to be managed in correctional settings. Smoking substances other than tobacco is common within prisons and, according to correctional officers interviewed for this evaluation, previously occurred in the NT. Similarly, 'standover' occurs in prisons for many different items, and previously occurred for cigarettes. 
A strength of this study is the qualitative data collected from participants who were directly affected by the policy. This captured a diversity of views and identified several issues that had not previously been reported in research into prison smoking bans. A potential limitation is that the interviewer $(\mathrm{MH})$ is a white female who does not speak any Aboriginal languages. Although she has extensive experience working in services for people who are socioeconomically disadvantaged, and broad cross-cultural experience, this may have adversely affected the willingness of some Indigenous prisoners, particularly males, to participate or discuss issues freely. For logistical reasons, we were also unable to interview prisoners in protection or maximum security. For prisoners serving lengthy sentences, there may be specific issues we have not identified.

A further limitation is that routine data collection was not designed to capture some relevant information that may have been an important source of data triangulation. For example, recording of incidents such as arguments and fights between prisoners was not coded by whether they were tobacco related. Even if this had been possible, under-recording of tobacco-related incidents would be likely, as it would rely on prisoner disclosure of reasons.

Our finding that NRT patch misuse is a significant issue is based on consistent reports from most participants. However, it was not possible to estimate or verify the extent of patch misuse, as records are not kept that would enable the nature of disciplinary incidents to be extracted. Limitations in routine data collection also meant that we were unable to accurately assess the use of contraband tobacco. However, reports from prisoners and staff suggest that, although contraband exists, the ban has not resulted in a significant new prison economy, as has been reported in some US jurisdictions. ${ }^{26}$

\section{Conclusion}

This study highlights the importance of generating 'buyin' from staff and prisoners to successfully introduce smoke-free prisons policies. NRT misuse is a key finding for correctional jurisdictions to consider when planning smoke-free facilities. It is also relevant for other closed institutional settings such as secure mental health facilities, as well as services providing free or low-cost NRT, where tobacco is unavailable or where the price differential offers an incentive for diversion. Priority should be given to minimising the risk of diversion in these settings. Important mechanisms include monitoring used patches (e.g. one-for-one exchange systems) and delivering health education about the potential dangers of smoking NRT patches.

\section{Acknowledgements}

We thank the NT Department of Correctional Services and staff, prisoners and prisoners' families who participated in this evaluation, and the NT Department of Health, which contributed funding. We also thank Dr Hana Morrissey and Professor Patrick Ball, of Charles Darwin University, for their input regarding NRT patch misuse.

\section{Competing interests}

David Thomas was a National Heart Foundation Research Fellow; funding from the fellowship supported this research. Robyn Hopkins is employed by the NT Department of Correctional Services.

\section{Author contributions}

All authors contributed to the conception and design of the study, data analysis and interpretation, drafting and revising of the manuscript, and approval of the submitted draft.

\section{References}

1. World Health Organization. Guidelines on protection from exposure to tobacco smoke. Geneva: World Health Organization; 2007 [cited 2015 Feb 20]. Available from: www.who.int/fctc/cop/art\%208\%20guidelines_english.pdf

2. Action on Smoking and Health. Fact sheet: smokefree prisons. Action on Smoking and Health; 2015 [cited 11 Apr 2016]. Available from: ash.org.uk/files/documents/ ASH_740.pdf

3. Scollo MM, Winstanley MH. Tobacco in Australia: facts and issues. Melbourne: Cancer Council Victoria; 2012 [cited 2014 Nov 11]. Available from: www. tobaccoinaustralia.org.au

4. Australian Institute of Health and Welfare. Smoking and quitting among prisoners in Australia 2012. Canberra: Australian Institute of Health and Welfare; 2013 [cited 2015 Feb 16]. Available from: www.aihw.gov.au/ publication-detail/?id=60129544877

5. Criminal Justice Research and Statistics Unit. Northern Territory Department of the Attorney-General and Justice. Annual statistics 2012-2013. Darwin: Northern Territory Government; 2014 [cited 2015 Feb 16]. Available from: www.nt.gov.au/justice/policycoord/researchstats/stats_ previous.shtml\#2012

6. Chondur R, Coffey P, Guthridge S. Smoking prevalence Northern Territory - 1994 to 2013. Health gains planning information sheet. Darwin: Northern Territory Department of Health; 2014 [cited 2015 Feb 16]. Available from: digitallibrary.health.nt.gov.au/prodjspui/handle/10137/603

7. Kennedy SM Davis SP, Thorne SL. Smoke-free policies in US prisons and jails: a review of the literature. Nicotine Tob Res. 2015;17(6):629-35. 
8. Lincoln T, Chavez RS, Langmore-Avila E. US experience of smoke-free prisons. BMJ. 2005;331(7530):1473.

9. Butler T, Richmond R, Belcher J, Wilhelm K, Wodak A. Should smoking be banned in prisons? Tob Control. 2007;16(5):291-3.

10. Richmond R, Indig D, Butler T, Wilhelm K, Arhcer V, Wodak A. A randomized controlled trial of a smoking cessation intervention conducted among prisoners. Addiction. 2013;108(5):966-74.

11. Richmond RL, Butler T, Belcher JM, Wodak A, Wilhelm K, Baxter E. Promoting smoking cessation among prisoners: feasibility of a multi-component intervention. Aust N Z J Public Health. 2006;30(5):474-8.

12. Cropsey KL, Kristeller JL. Motivational factors related to quitting smoking among prisoners during a smoking ban. Addict Behav. 2003;28(6):1081-93.

13. Cropsey KL, Kristeller JL. The effects of a prison smoking ban on smoking behavior and withdrawal symptoms. Addict Behav. 2005;30(3):589-94.

14. Collinson L, Wilson N, Edwards R, Thomson G, Thornley S. New Zealand's smokefree prison policy appears to be working well: one year on. N Z Med J. 2012;125(1357):164-8.

15. Dorsett J. Australian Broadcasting Corporation. Queensland announces plans to ban smoking in all jails from May 2014; 2013 [cited 2014 Nov 24] [about 2 screens]. Available from: www.abc.net.au/news/2013-1103/qld-prison-smoking-ban/5066404

16 Royal Australian College of General Practitioners. Supporting smoking cessation: a guide for health professionals. Melbourne: Royal Australian College of General Practitioners; 2014 [cited 2015 Feb 16]. Available from: www.racgp.org.au/your-practice/ guidelines/smoking-cessation/

17. Australian Institute of Health and Welfare. Prisoner health services in Australia 2012. Canberra: Australian Institute of Health and Welfare; 2014 [cited 2015 Nov 16]. Available from: www.aihw.gov.au/publicationdetail/?id=60129548273

18. Pawson R, Tilley N. Realist evaluation. London: British Cabinet Office; 2004 [cited 2015 Feb 16]. Available from: www.communitymatters.com.au/RE_chapter.pdf
19. Vaismoradi M, Turunen H, Bondas T. Content analysis and thematic analysis: implications for conducting a qualitative descriptive study. Nurs Health Sci. 2013;15(3):398-405.

20. Morrissey H, Ball P, Boland M, Hefler M, Thomas DP. Constituents of smoke from cigarettes made from diverted nicotine replacement therapy patches. Drug Alcohol Rev. 2015;doi: 10.1111/dar.12288 [Epub ahead of print].

21. Foley KL, Proescholdbell S, Herndon Malek S, Johnson J. Implementation and enforcement of tobacco bans in two prisons in North Carolina: a qualitative inquiry. J Correct Health Care. 2010;16(2):98-105.

22. Lando HA, Michaud ME, Poston WS, Jahnke SA, Williams L, Haddock CK. Banning cigarette smoking on US Navy submarines: a case study. Tob Control. 2015;(e3):e188-92.

23. Campion J, Lawn S, Brownlie A, Hunter E, Gynther B, Pols R. Implementing smoke-free policies in mental health inpatient units: learning from unsuccessful experience. Australas Psychiatry. 2008;16(2):92-7.

24. Zhou X, Nonnemaker J, Sherrill B, Gilsenan AW, Coste F, West R. Attempts to quit smoking and relapse: factors associated with success or failure from the ATTEMPT cohort study. Addict Behav. 2009;34(4):365-73.

25. Thibodeau L, Seal DW, Jorenby DE, Corcoran K, Sosman JM. Perceptions and influences of a state prison smoking ban. J Correct Health Care. 2012;18(4):293-301.

26. Ferranti S. The Daily Beast. With cigarettes banned in most prisons, gangs shift from drugs to smokes; 2013 [cited 2014 Nov 11] [about 6 screens]. Available from: www.thedailybeast.com/articles/2013/06/02/withcigarettes-banned-in-most-prisons-gangs-shift-fromdrugs-to-smokes.html

\section{Copyright: (c)}

(c) 2016 Hefler et al. This article is licensed under the Creative Commons Attribution-NonCommercial-ShareAlike 4.0 International Licence, which allows others to redistribute, adapt and share this work non-commercially provided they attribute the work and any adapted version of it is distributed under the same Creative Commons licence terms. See: www.creativecommons.org/licenses/by-nc-sa/4.0/ 